\title{
Outcomes after sofosbuvir-containing regimens for hepatitis $C$ virus in patients with decompensated cirrhosis: a real-world study
}

Fanpu $\mathrm{ji}^{1,2^{*}} \mathbb{B}$, Wenjun Wang ${ }^{1}$, Shuangsuo Dang ${ }^{1}$, Shengbang Wang ${ }^{1}$, Burong $\mathrm{Li}^{3}$, Dan Bai ${ }^{4}$, Wenxue Zhao ${ }^{1}$, Hong Deng ${ }^{1}$, Changyin Tian $^{1 *}$ and Zongfang Li $i^{2,5}$

\begin{abstract}
Background: Direct-acting antivirals have been used for decompensated cirrhotic patients with hepatitis $C$ virus (HCV) infection. However, the benefits in Chinese patients with decompensated cirrhosis are unclear.

Methods: Thirty patients with HCV infection and decompensated cirrhosis were administered sofosbuvir-containing regimens at our hospital between April and December 2015. The efficacy and safety of the treatments was determined by sustained virological response at week 12 (SVR 12), change of liver function and adverse events.

Results: The cohort included 13 treatment-experienced and 17 treatment-naïve patients. A total of 27 patients (90\%) achieved SVR 12. No baseline characteristics (sex, age, treatment-experience, genotype, viral load, liver function or splenectomy) was association with achievement of SVR 12. Patients achieved SVR 12 had significantly improved liver function by post-treatment week $12(P<0.05)$. Of the 30 patients, six developed anemia, one developed hepatic decompensation, two developed impaired renal function and one developed a severe upper respiratory tract infection during the treatment. There was no death or HCC development during 12 months of follow-up off-therapy. Two patients (7.4\%) with SVR 12 experienced new decompensated episodes during the follow-up.

Conclusion: Sofosbuvir-containing regimens are effective in Chinese HCV patients with decompensated cirrhosis, regardless of baseline characteristics, as demonstrated by a high rate of SVR 12, as well as improvement in liver function. Although antiviral therapy is generally well tolerated, a vigilant monitoring of anemia and renal function should be mandatory.
\end{abstract}

Keywords: Hepatitis C virus, Sofosbuvir, Child-Pugh score, Decompensated cirrhosis, Renal dysfunction, Anemia

\section{Background}

Hepatitis $\mathrm{C}$ virus $(\mathrm{HCV})$ infection is a global health problem with an estimated disease burden affecting 130-170 million people. China, with a prevalence of $0.6-2.0 \%$, has the most people (more than 10 million) with chronic $\mathrm{HCV}$ infection worldwide [1, 2]. Chronic hepatitis $\mathrm{C}(\mathrm{CHC})$ represents a life-threatening condition, especially if left untreated, as it is leads to

\footnotetext{
* Correspondence: jifanpu1979@163.com; lbdtcyty@163.com 'Department of Infectious Diseases, Second Affiliated Hospital of Xi'an Jiaotong University, 157 Xi Wu Road, Xi'an 710004, Shaanxi Province, People's Republic of China

Full list of author information is available at the end of the article
}

development of cirrhosis, a liver disease that is accompanied by high risk of progression to hepatic decompensation and hepatocellular carcinoma (HCC) [1-3]. Despite advances in screening strategies and effective antiviral therapy, the number of patients with $\mathrm{HCV}$ related decompensated cirrhosis is projected to rise over the next decade or more $[2,4,5]$.

$\mathrm{HCV}$ eradication in compensated and decompensated cirrhotic patients after interferon (IFN)-based antiviral therapy is associated with improvement of liver metabolic activity, prevention of $\mathrm{HCV}$ recurrence after transplantation, and removal of some patients from the waiting list for liver transplant, as well as reduced risk of HCC 
development [6-12]. Unfortunately, IFN-based antiviral therapy for cirrhotic patients with advanced disease is also associated with poor tolerability, serious infections and increased risk of death [10-13]. The advent of direct-acting antiviral agents (DAAs) promises to overcome these disadvantages in safety while increasing efficacy.

Sofosbuvir is a nucleotide analogue inhibitor of the HCV-encoded NS5B polymerase, and has been approved for treatment of genotypes 1-4 [14]. Sofosbuvir in combination with other DAAs (such as ledipasvir, daclatasvir, velpatasvir, simeprevir) with or without ribavirin has been reported to attain a sustained virologic response (SVR) rate of over 90\% when administered as a 12- to 24-week course, while being well-tolerated in cirrhotic patients with advanced disease as well as in liver transplant patients through both clinical trials and real-world evidence [15-24]. Moreover, the sofosbuvir-based therapy also has been shown to improve liver function and halt liver disease progression in cirrhotic patients with advanced disease $[15,19,20]$. Despite of the impact of DAAs treatments on the risk of $\mathrm{HCC}$ occurrence in patients without $\mathrm{HCC}$ or on the risk of tumor recurrence after curative treatment of HCC remains controversial [25-29].

To date, few report of DAAs treatment of Chinese patients with $\mathrm{HCV}$ infection and decompensated cirrhosis exists in available literature without the data of followup off-therapy [30, 31]. Therefore, the objective of present study was to share our real-world experience of effectiveness and safety of sofosbuvir-containing regimens for $\mathrm{HCV}$ in patients with decompensated cirrhosis in a tertiary hospital in northwest China.

\section{Methods}

\section{Study design and patients}

This study complied with the Declaration of Helsinki. The institutional review board of the Second Affiliated Hospital of Xi'an Jiaotong University waived the requirement for approval of this retrospective study. Patients were offered study enrollment upon meeting the following inclusion criteria: positive anti-HCV and HCV RNA at last 3 months; on admission, Child-Pugh score $\geq 7$ or $\leq 6$ points and at least one pre-admission event signifying hepatic decompensation, including ascites, variceal bleeding, spontaneous bacterial peritonitis (SBP) or hepatic encephalopathy. Patients with HCC, chronic renal failure, unstable cardiovascular disease, severe chronic obstructive lung disease, coinfection with human immunodeficiency virus, or Child-Pugh class $\mathrm{C}$ after the decompensated event who had been treated with appropriate therapy were denied study enrollment. Among those patients who met the criteria for study enrollment, only those who were willing to accept and adhere to the prescribed drug and regimen were included in the final study population.

In total $84 \mathrm{HCV}$ related decompensated cirrhotic patients were screened for treatment in our hospital from April to December 2015. Fifteen of them were excluded for negative HCV RNA (14 of 15 patients with successful HCV treatment by IFN-based regimens), 13 were excluded for HCC, 12 for refusing to be treated with sofosbuvir-containing regimens, ten for Child-Pugh class $\mathrm{C}$ and four for severe complications including chronic kidney disease $(n=2)$, cardiovascular disease $(n=1)$ and severe chronic obstructive lung disease $(n=1)$. The remaining 30 patients were enrolled into the study (Fig. 1) included 13 treatment-experienced patients $[8,11,32,33]$ and 17 treatment-naïve patients.

\section{Treatment schedules}

Antiviral treatment started 1- to 2-weeks after the decompensated event had been treated with appropriate therapy such as antibiotic treatment for SBP, diuretics for ascites and edema, etc. Prior to initiation of the sofosbuvir-containing therapeutic regimens, each patient underwent electrocardiogram, endoscopy, liver computed tomography (CT)/B ultrasound, $\alpha$ fetoprotein and virus genotyping (Da An Gene Co. Ltd. of Sun Yat-Sen University, China). Twenty-one (70\%) of the patients were infected with HCV genotype $1 \mathrm{~b}$. Among these patients, two were treated with sofosbu$\operatorname{vir}(400 \mathrm{mg} / \mathrm{d})+$ ledipasvir $(90 \mathrm{mg} / \mathrm{d})$ for 16 weeks, three were treated with sofosbuvir $(400 \mathrm{mg} / \mathrm{d})+$ daclatasvir $(60 \mathrm{mg} / \mathrm{d})$ for $12-16$ weeks, 15 were treated with sofosbuvir $(400 \mathrm{mg} / \mathrm{d})+$ ribavirin $(900-1200 \mathrm{mg} / \mathrm{d})$ for 24 weeks, and one was treated with triple-combination therapy of sofosbuvir $(400 \mathrm{mg} / \mathrm{d})+$ pegylated interferon alpha-2b (Peg-IFN $\alpha$-2b $) \quad(80 \quad \mu g / w k)+$ ribavirin $(1000 \mathrm{mg} / \mathrm{d})$ for 12 weeks. All of the nine patients with $\mathrm{HCV}$ genotype $2 \mathrm{a}$ infection were treated with sofosbuvir $(400 \mathrm{mg} / \mathrm{d})+$ ribavirin $(900 \mathrm{mg} / \mathrm{d})$ for $16-24$ weeks. For patient showed decrease in hemoglobin to 9.0 $10.0 \mathrm{~g} / \mathrm{dL}$ required closely monitored, to $8.0-9.0 \mathrm{~g} / \mathrm{dL}$ required ribavirin dose reductions, to less than $8.0 \mathrm{~g} /$ $\mathrm{dL}$ required ribavirin discontinuations and received erythropoietin treatment, which was referred to our previous studies of IFN-based treatment for this population $[8,11,33]$. The treatment regimens and effectiveness were presented in Fig. 1.

\section{Treatment monitoring and follow-up}

Patients receiving therapy were reviewed at treatment weeks 2, 4 and 12 and/or end of treatment, and at post-treatment weeks 4 and 12, and then once every 3 months subsequently. Partial patients underwent HCV RNA testing at days 3, and 7 of treatment. The 


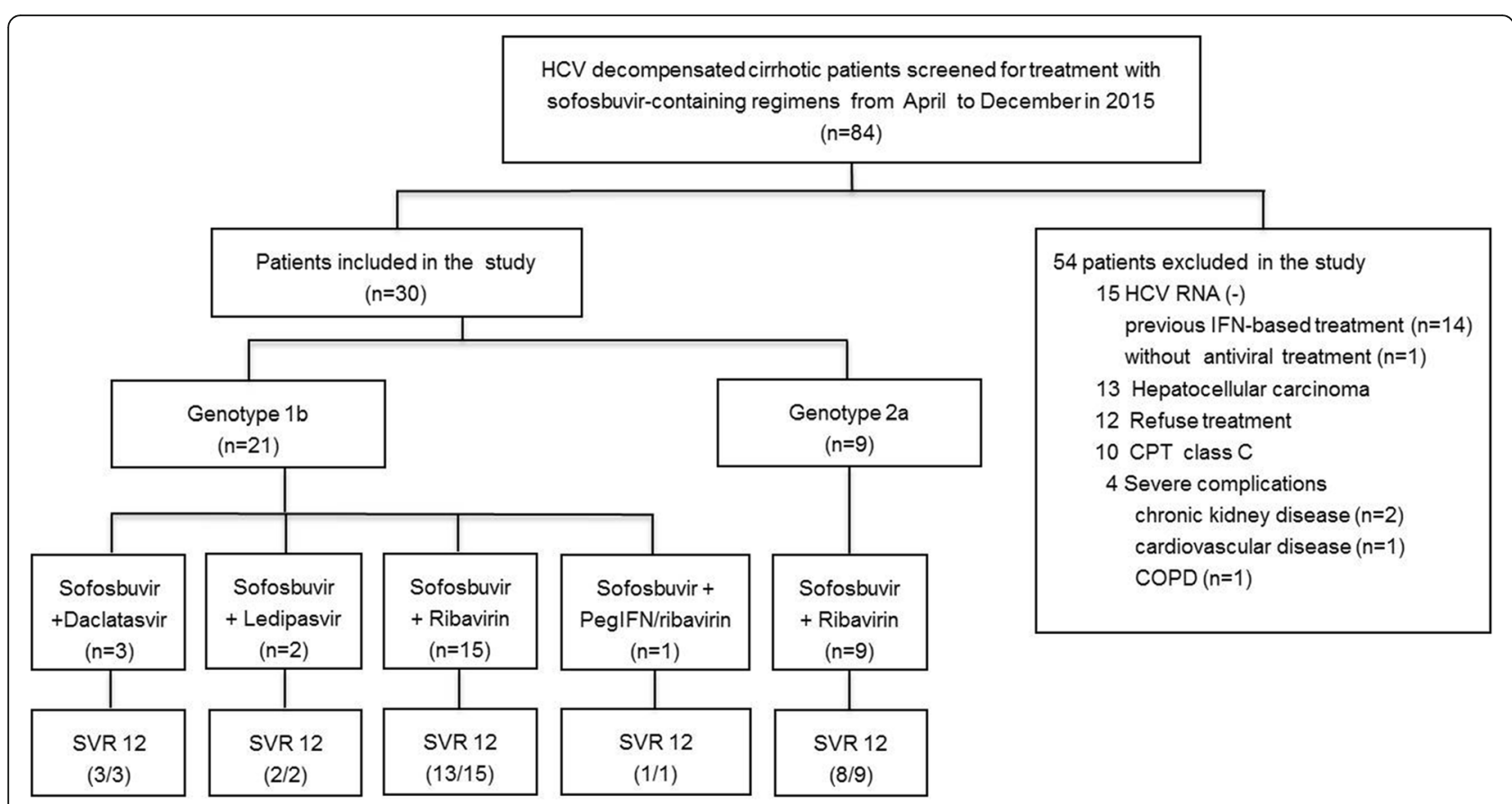

Fig. 1 Antiviral therapy regimens and virologic response in patients with decompensated cirrhosis. COPD, chronic obstructive lung disease

blood cell count, HCV RNA and serum markers including total bilirubin (TBIL), alanine aminotransferase (ALT), albumin (ALB), urea nitrogen and serum creatinine, prothrombin activity (PTA) were checked in each review routinely. All patients received liver B ultrasound and $\alpha$-fetoprotein test every 3 months after DAAs treatment for HCC screening. And patient also received liver computed tomography with or without contrast enhancement scan when it is necessary to rule out HCC development. HCV RNA was measured using the 7300 real-time PCR system (Applied Biosystems Inc., USA) and reagents from the Da An Gene Co. Ltd. of Sun Yat-Sen University, China. However, the Cobas TaqMan quantitative detection kit, with a detection limit $<25 \mathrm{IU} / \mathrm{mL}$, was used to measure HCV RNA at end-oftreatment and post-treatment week 12. Serious adverse events (SAEs), decompensation events, severe infections, HCC development and death were recorded. Other common adverse events (AEs), such as palpitation, dizziness, nausea, fatigue etc., were also recorded.

\section{Outcome measures}

The primary end point of our study was sustained virological response at 12 weeks post-treatment (SVR 12), which was defined as undetectable HCV RNA measured with a detection limit of quantification $<25 \mathrm{IU} / \mathrm{mL}$. The secondary end points included undetectable HCV RNA at treatment week 1,2 or 4, change in liver function (serum TBIL, ALT, ALB, PTA and Child-Pugh score) at post-treatment week 12, AEs including liver decompensation and HCC development during the treatment and follow-up period. The length of the follow-up period was calculated from the end of the antiviral treatment to the last follow-up visit.

\section{Statistical analysis}

Data are represented as the mean and standard deviation or as absolute and relative frequencies. Statistical comparisons were carried out using the chi-square test or Fisher's exact test for baseline characteristics, and the two-sided paired $t$-test for the change in liver function at baseline and post-treatment week 12 . The following baseline characteristics were examined in relation to SVR 12: patient age $>60$ years, sex, treatment-experienced, $\mathrm{HCV}$ genotype, baseline viral load $\geq 1.0 \times 10^{6} \mathrm{IU} / \mathrm{mL}$, Child-Pugh score $\geq 7$, and splenectomy. Analyses were carried out using SPSS statistical software, version 17.0 (IBM, Chicago, IL, USA). A $p$-value of $<0.05$ was set as the threshold for statistical significance.

\section{Results}

Patient demographics and clinical characteristics

The 30-patient cohort consisted of 8 males and $22 \mathrm{fe}$ males, with a mean age of $58.57 \pm 8.06$ years-old (range: 42-73 years-old). Among the 30 patients, 13 (43.3\%) had previously been administered an IFNbased regimen and showed treatment failure including 
relapse and non-virological response; the remaining 17 patients were treatment-naïve. The collective characteristics are presented in Table 1.

\section{Virological outcome}

SVR 12 was achieved in 27/30 (90\%) for this population of HCV decompensated cirrhotic patients. For the various treatment regimens administered (Fig. 1), two of the patients infected with genotype $1 \mathrm{~b}$ who received the sofosbuvir + ribavirin therapy experienced relapse at weeks 4 and 12 after end-of-treatment respectively, and one of them was treatment-naïve. Another treatment-naïve patient infected with genotype $2 \mathrm{a}$ who received sofosbuvir + ribavirin for 16 weeks experienced $\mathrm{HCV}$ recurrence at post-treatment week 12 .

No baseline factors, including sex (SVR in males, $100 \%$ vs. in females, $86.3 \%$ ), age (SVR in $\geq 60$ years-old, $92.9 \%$ vs. $<60$ years-old, $87.5 \%$ ), previous IFN-based therapy experience (SVR in treatment-experienced, $92.3 \%$ vs. treatment-naïve, $88.2 \%$ ), virus genotype (SVR in 1b-infected, $90.5 \%$ vs. 2a-infected, $88.9 \%$ ), baseline viral load (SVR in $\geq 10^{6} \mathrm{IU} / \mathrm{mL}, 87.5 \%$ vs. $<10^{6} \mathrm{IU} / \mathrm{mL}, 92.9 \%$ ), Child-Pugh score (SVR in $\geq 7,88.9 \%$ vs. $<7,90.5 \%$ ) and previous splenectomy treatment (SVR in splenectomy, $88.9 \%$ vs. no splenectomy, $90.5 \%)$ was associated with the achievement of SVR 12 (all $p>0.05$ ) (Fig. 2).

Serum HCV RNA was detected in 12 patients 3 days after receiving antiviral treatment with sofosbuvircontaining regimens. There was an average reduction in HCV RNA viral load by $3.34 \log 10$ (baseline, $6.06 \pm 0.62$ vs. treatment day $3,2.72 \pm 1.33$ ). The rates of undetectable
$\mathrm{HCV}$ during treatment were $54.8 \%(7 / 13)$ at week 1 , $83.3 \%(15 / 18)$ at week $2,100 \%(30 / 30)$ at week 4 and $100 \%(30 / 30)$ at end-of-treatment.

\section{Effects of sofosbuvir-containing regimens on liver func- tion and safety}

The sofosbuvir-containing treatment led to significant improvements in liver function (baseline vs. post-treatment week 12; Table 2). Totally, 14 patients (46.7\%) experienced at least one AEs, four patients (13.3\%) experienced SAEs. Of these SAEs, two patients experienced increase in serum urea nitrogen and/or serum creatinine to levels above the upper limit of normal. Another one patient developed severe anemia ( $5.6 \mathrm{~g} / \mathrm{dL}$ in hemoglobin) accompanied by liver decompensation, massive ascites, and lower extremity edema; the complications were severe enough to require hospitalization and a 3-week discontinuation of the ribavirin therapy. The remains patient developed a severe upper respiratory tract infection, which was resolved with cefatriaxone treatment, administered for 5 days.

Anemia (20\%) was the most common AEs, all of the six patients experienced a more than $2.0 \mathrm{~g} / \mathrm{dL}$ decrease in hemoglobin, who received a treatment regimen containing ribavirin $(n=25)$. Among them, four and two patients showed decrease in hemoglobin to less than $10.0 \mathrm{~g} / \mathrm{dL}$ and $8.0 \mathrm{~g} / \mathrm{dL}$, respectively. The former responded to a reduction in the ribavirin dosage, while the other two required to interrupted ribavirin and received erythropoietin treatment. Of the 25 patients received ribavirin-containing regimens treatment, the

Table 1 Patient demographics and clinical characteristics

\begin{tabular}{|c|c|c|c|}
\hline Characteristic & Treatment-naïve patients $(n=17)$ & Treatment-experienced patients $(n=13)$ & All patients, $(n=30)$ \\
\hline \multicolumn{4}{|l|}{ Sex, n (\%) } \\
\hline $\begin{array}{l}\text { Male } \\
\text { Female }\end{array}$ & $\begin{array}{l}4(23.5) \\
13(76.5)\end{array}$ & $\begin{array}{l}4(30.8) \\
9(69.2)\end{array}$ & $\begin{array}{l}8(26.7) \\
22(73.3)\end{array}$ \\
\hline \multicolumn{4}{|l|}{ Age, n (\%) } \\
\hline $\begin{array}{l}\geq 60 \text { years-old } \\
<60 \text { years-old }\end{array}$ & $\begin{array}{l}7(41.2) \\
10(58.8)\end{array}$ & $\begin{array}{l}7(53.8) \\
6(46.2)\end{array}$ & $\begin{array}{l}14(46.7) \\
16(53.3)\end{array}$ \\
\hline \multicolumn{4}{|l|}{ Genotype ${ }^{a}, \mathrm{n}(\%)$} \\
\hline $\begin{array}{l}1 b \\
2 a\end{array}$ & $\begin{array}{l}9(52.3) \\
8(47.7)\end{array}$ & $\begin{array}{l}12(92.3) \\
1(7.7)\end{array}$ & $\begin{array}{l}21(70.0) \\
9(30.0)\end{array}$ \\
\hline \multicolumn{4}{|l|}{ HCV RNA, n (\%) } \\
\hline $\begin{array}{l}\geq 1.0 \times 10^{6} \mathrm{IU} / \mathrm{mL} \\
<1.0 \times 10^{6} \mathrm{IU} / \mathrm{mL}\end{array}$ & $\begin{array}{l}7(41.2) \\
10(58.8)\end{array}$ & $\begin{array}{l}9(69.2) \\
4(30.8)\end{array}$ & $\begin{array}{l}16(53.3) \\
14(46.7)\end{array}$ \\
\hline \multicolumn{4}{|l|}{ Child-Pugh score ${ }^{a}, \mathrm{n}(\%)$} \\
\hline $\begin{array}{l}\geq 7 \\
<7\end{array}$ & $\begin{array}{l}7(41.2) \\
10(58.8)\end{array}$ & $\begin{array}{l}2(15.4) \\
11(84.6)\end{array}$ & $\begin{array}{l}9(30.0) \\
21(70.0)\end{array}$ \\
\hline \multicolumn{4}{|l|}{ Splenectomy, n (\%) } \\
\hline $\begin{array}{l}\text { Yes } \\
\text { No }\end{array}$ & $\begin{array}{l}6(35.3) \\
11(64.7)\end{array}$ & $\begin{array}{l}3(23.1) \\
10(76.9)\end{array}$ & $\begin{array}{l}9(30.0) \\
21(70.0)\end{array}$ \\
\hline
\end{tabular}

\footnotetext{
${ }^{a}$ Compared with the treatment-naïve patients, a lower proportion of treatment- experienced patients is genotype 2 and Child-Pugh score $\geq 7 ; p<0.05$
} 


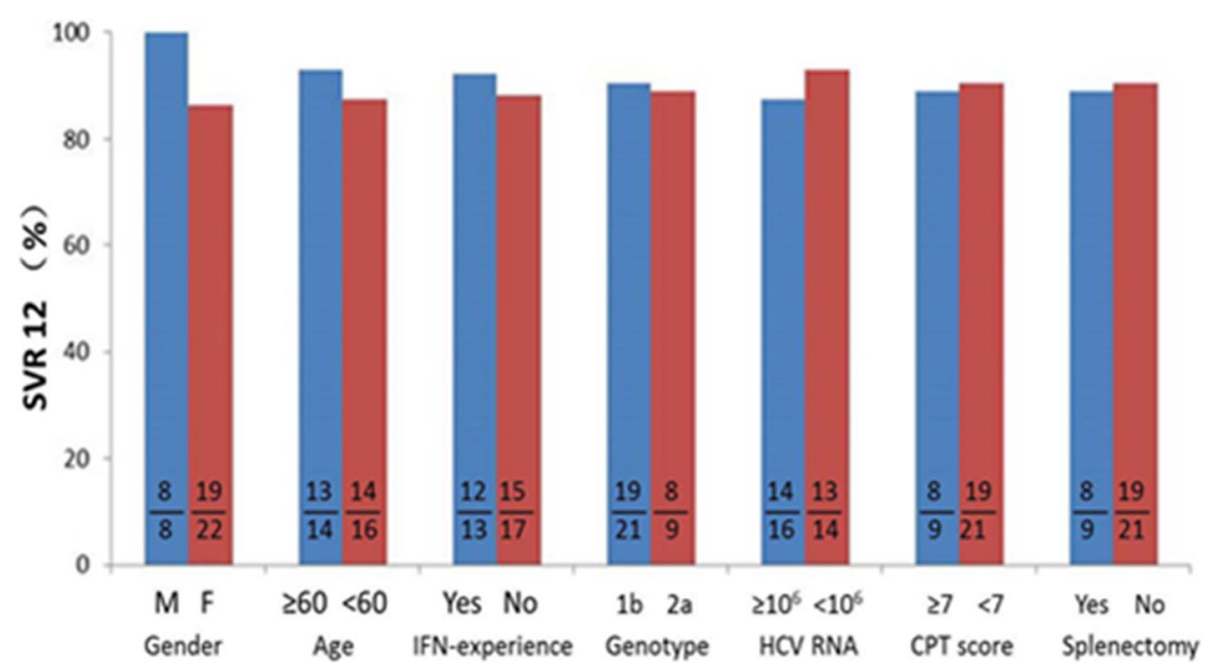

Fig. 2 SVR 12 by baseline factor

hemoglobin was significantly reduced at the end-oftreatment, compare to those at baseline $(11.5 \pm 1.08$ vs. $10.7 \pm 0.96 \mathrm{~g} / \mathrm{dL}, P=0.013)$. Despite the hemoglobin reelevated to a level of similar to baseline at 12 weeks posttreatment $(11.5 \pm 1.08$ vs. $11.6 \pm 0.99 \mathrm{~g} / \mathrm{dL}, P=0.546)$. There were no different of hemoglobin at baseline, endof-treatment and 12 week post-treatment for five patients treated with ribavirin-free regimens. Other AEs included nausea, fatigue, palpitation, pruritus/rash, dizziness/headache, shortness of breath, and sleep disorders (Table 3).

\section{Outcome of follow-up off-therapy}

There was no death or HCC development during antiviral therapy and the median 12 (range 8-15) months of follow-up off-therapy. And none of the patients need for liver transplant, although two of the 27 patients with SVR 12 experienced new decompensated episodes of encephalopathy and ascites in 4 and 9 month after end-oftreatment, respectively.

\section{Discussion}

Overall estimates indicate that up to $15 \%$ of patients with chronic HCV infection progress to cirrhosis within 20 years. Liver cirrhosis progression to the decompensated stage has an annual incidence of about $3-4 \%$ [1, 2]. Once decompensated HCV-related cirrhosis is established, patients have a poor prognosis, and are characterized by a very high frequency of readmission, development of decompensation different from the initial one, a generally low quality of life, and high risk of mortality [1, 2, 34, 35]. Thus, a highly safe and effective regimen for all genotypes of $\mathrm{HCV}$ infection in patients with decompensated liver disease would address a significant unmet medical need.

Studies have shown that more than $90 \%$ patients achieve SVR 12 after DAAs treatment with or without ribavirin, and the treatment led to early improvements in hepatic function $[15,16,18-20]$. Therefore, the European Association for Study of Liver (EASL) does not recommend IFN-based regimens for patients with decompensated cirrhosis; instead, patients with genotype 2 infections are recommend to be treated with sofosbuvir + ribavirin for 16-20 weeks, and patients with genotype 1 infections are recommend to be treated with sofosbuvir + ledipasvir or sofosbuvir + daclatasvir with or without ribavirin for 12 or 24 weeks [36]. The treatment combination of sofosbuvir + velpatasvir has also been shown to have excellent efficacy and safety profiles in patients with decompensated cirrhosis [15]. In general, however, studies of DAAs in Chinese populations are lacking, due to the slow approval process and high cost of DAAs drugs. And our findings presented herein

Table 2 Liver function markers pre- and post-treatment week $12(n=30)$

\begin{tabular}{llllll}
\hline & TBIL, in $\mu \mathrm{mol} / \mathrm{L}$ & ALT, in IU/L & ALB, in g/L & PTA, in \% & Child-Pugh score \\
\hline Baseline & $23.48 \pm 12.54$ & $50.17 \pm 32.93$ & $39.52 \pm 5.73$ & $76.17 \pm 16.80$ & $6.30 \pm 1.60$ \\
Post-treatment week 12 & $18.98 \pm 9.24$ & $25.70 \pm 10.67$ & $42.96 \pm 6.17$ & $79.85 \pm 14.62$ & $5.87 \pm 1.14$ \\
$t$-value & 3.371 & 3.973 & 4.214 & 2.544 & 2.642 \\
$p$-value & 0.002 & 0.000 & 0.000 & 0.017 & 0.013 \\
\hline
\end{tabular}

ALB albumin, ALT alanine aminotransferase, PTA prothrombin activity, TBIL total bilirubin 
Table 3 Summary of adverse event during the treatment period $(n=30)$

\begin{tabular}{ll}
\hline Patients with adverse event & Number (\%) \\
\hline Any adverse event & $14(46.7)$ \\
Serious adverse event & $4(13.3)$ \\
Renal dysfunction & $2(6.7)$ \\
Hepatic decompensation & $1(3.3)$ \\
Upper respiratory tract infection & $1(3.3)$ \\
Discontinuation due to adverse event & $3(10)$ \\
Death & $0(0)$ \\
Common adverse event & \\
Anemia & $6(20)$ \\
Nausea & $3(10)$ \\
Fatigue & $2(6.7)$ \\
Palpitation & $2(6.7)$ \\
Pruritus/rash & $2(6.7)$ \\
Dizziness/headache & $2(6.7)$ \\
Shortness of breath & $1(3.3)$ \\
Sleep disorders & $1(3.3)$ \\
\hline
\end{tabular}

provide the clinical experience of sofosbuvir-containing regimens for Chinese patients with hepatitis $\mathrm{C}$ and decompensated cirrhosis.

Our results show that the sofosbuvir-containing treatment regimens are well tolerated in this patient population, and provide a very good efficacy, regardless of baseline characteristics. All of the 27 patients in our study who achieved SVR 12 continued to show undetectable levels of HCV RNA up to post-treatment week 24. These results are in agreement with the recently reported multi-center clinical research study from China and Korea that showed that patients with genotype $1 \mathrm{~b}$ infection who are ineligible/intolerant to IFN therapies respond well to daclatasvir + asunaprevir combination therapy [37]. In our study, patients who achieved SVR 12 showed significant improvements in liver function, including TBIL, ALT, ALB, PTA and Child-Pugh score post-treatment week 12, which was consistent with the previous studies $[15,16,18-20]$. However, the longer term impact of DAAs treatment in patients with decompensated cirrhosis remains unknown. Sustained virologic response to IFN-based antiviral therapy decreases the incidence of HCC and the risk of hepatic decompensation in patients with HCV cirrhosis [6-11]. SVR after DAAs treatment reduces the incidence of $\mathrm{HCC}$ in patients with $\mathrm{CHC}$ and compensated cirrhosis had been reported recently [26]. For patients with decompensated cirrhosis, Cheung et al. suggested antiviral therapy led to prolonged improvement in liver function without evidence of an increased risk of HCC development after 15 months follow-up off- therapy [19]. However, other studies showed unexpected high incidence of HCC in cirrhotic patients with SVR following IFN-free DAAs treatment [25, 27, 28]. None of our patients occurred HCC or death, and only $7.4 \%$ of patients with SVR 12 experienced new decompensated episodes during the median 12 (range 8-15) months of follow-up off-therapy. Thus, patient with decompensated cirrhosis can benefit from antiviral therapy with DAAs.

Although ribavirin treatment was not associated with hepatic decompensation, $30.4 \%$ and $5.4 \%$ patients with compensated and decompensated cirrhosis need ribavirin dose reductions and discontinuations respectively [38]. Anemia was the most common AEs, and all of them presented in patients with ribavirin-containing regimen in our study. Thus, it appears that the ribavirin component may be responsible for the side effect of anemia. However, all of the six patients with ribavirin dose reductions and/or discontinuations achieved SVR 12, which add further evidence of ribavirin dose adjustment in cirrhotic patients with advanced disease should not reduce efficacy of antiviral treatment by Saxena et al. [38].

Two additional patients experienced renal adverse reaction, as evidenced by increased serum urea nitrogen/ creatinine and decreased glomerular filtration rate (GFR). Both of them responded to a 2-week discontinuation of antiviral treatment, along with management using benazepril and prostaglandin E1. Re-initiation of the sofosbuvir + ribavirin treatment, after the patients showed improvement of renal dysfunction, were well tolerated. Ultimately, both of the patients completed the antiviral treatment and achieved SVR 12. Sofosbuvir is primarily metabolized by the kidney. Studies have shown that patients with $\mathrm{HCV}$ infection and decompensated cirrhosis and who underwent liver transplantation can experience reduced GFR or even acute renal failure during pre- and post-transplantation therapy with a sofosbuvir-based regimens [15, 18, 38]. However, studies also had shown that sofosbuvir-based regimen using dosage of $400 \mathrm{mg}$ is effective and safe in patients with end-stage renal disease undergoing hemodialysis or who have GFR $<30 \mathrm{~mL} / \mathrm{min}[39,40]$.

Considering the potential risk of hepatorenal syndrome or acute kidney injury in patients with endstage liver disease, and both sofosbuvir and ribavirin are mainly through kidney metabolism, patients with hepatitis $C$ infection and decompensated cirrhosis who are administered a sofosbuvir-containing regimen with or without ribavirin require close monitoring of renal function. If renal damage occur or aggravate, treatments should be given to improve renal function, and short interruption or dose reductions of antiviral treatment may be necessary [38], as was evidenced in cases in our study. 
Limits of this retrospective study include heterogeneity of antiviral treatments, a relatively small number of cases, limited length of follow-up and possible selection bias. In particular, due to the urgency of treatment, the accessibility of drugs during the study period, as well as the rapid movement in the field of anti-HCV treatment and the dramatic improvement in efficacy and safety of DAAs, not all patients received the antiviral therapy program recommended by current guidelines [36, 41, 42], such as 15 GT 1-infected patients received sofosbuvir + ribavirin treatment for 24 weeks. Again, due to the nature of retrospective study, there were different sofosbuvir-containing regimens with or without ribavirin, which potential preclude useful comparison in the statistical analysis. Furthermore, we enrolled only patients with mild to moderate liver decompensation, so our results cannot be generalized to patients with more severe liver disease. Finally, these results also cannot be extrapolated widely to all patients with mild to moderate liver decompensation. Despite these limitations, several conclusions can be drawn based upon careful consideration of the available data.

\section{Conclusions}

Sofosbuvir-containing regimens produced high rates of SVR 12 in decompensated cirrhotic patients, regardless of baseline characteristics. Antiviral treatment was associated with improvement in liver function, and was generally well tolerated in this Chinese population. However, a vigilant monitoring of anemia and renal dysfunction should be mandatory. Results from currently ongoing large and well-designed long-term study (ClinicalTrials.gov number, NCT01457755) [15] is awaited to verify the benefit and safety of sofosbuvir-containing regimens for decompensated cirrhotic patients with $\mathrm{HCV}$ infection including the risk of HCC development and long-term survival.

\section{Abbreviations}

ALB: Albumin; ALT: Alanine aminotransferase; CHC: Chronic hepatitis C; DAAs: Direct-acting antiviral agents; GFR: Glomerular filtration rate; HCC: Hepatocellular carcinoma; HCV: Hepatitis C virus; PTA: Prothrombin activity; SBP: Spontaneous bacterial peritonitis; SVR 12: Sustained virological response at week 12; TBIL: Total bilirubin

\section{Acknowledgments}

Not applicable.

\section{Funding}

This work was supported by the National Natural Science Foundation of China (No. 81300322) and Personnel training special funds of the Second Affiliated Hospital of Xi'an Jiaotong University [RC(GG)201,501]. The funding source had no involvement in writing the report.

\section{Availability of data and materials}

A majority of data generated or analyzed during this study are included in this published article. The datasets used and/or analyzed during the current study available from the corresponding author on reasonable request.

\section{Grant support}

This work was supported by the National Natural Science Foundation of China (No. 81300322) and Personnel training special funds of the Second Affiliated Hospital of Xi'an Jiaotong University [RC(GG)201,501]. The funding source had no involvement in writing the report.

\section{Authors' contributions}

All authors collaborated in the study design; FPJ, SSD, WXZ, HD, and CYT participated in diagnosing and managing these patients; FPJ, WJW, SBW, BRL, DB and CYT extracted and analyzed the clinical data; FPJ, WJW, BRL, DB and ZFL elucidated the data and carried out statistical analysis; FPJ prepared the first manuscript draft; CYT and ZFL modified the manuscript subsequently; all authors read and approved the final manuscript.

\section{Ethics approval and consent to participate}

The institutional review board of the Second Affiliated Hospital of Xi'an Jiaotong University waived the requirement for approval of this retrospective study.

\section{Consent for publication}

Not applicable.

\section{Competing interests}

The authors declare that they have no competing interests.

\section{Publisher's Note}

Springer Nature remains neutral with regard to jurisdictional claims in published maps and institutional affiliations.

\section{Author details}

'Department of Infectious Diseases, Second Affiliated Hospital of Xi'an Jiaotong University, 157 Xi Wu Road, Xi'an 710004, Shaanxi Province, People's Republic of China. ${ }^{2}$ Shaanxi Provincial Clinical Research Center for Hepatic \& Splenic Diseases, Second Affiliated Hospital of Xi'an Jiaotong University, Xi'an, China. ${ }^{3}$ Department of Clinical Laboratory, Second Affiliated Hospital of Xi'an Jiaotong University, Xi'an, China. ${ }^{4}$ Department of Biochemistry and Molecular Biology, Medical College of Xi'an Jiaotong University, Xi'an, China. ${ }^{5}$ National \& Local Joint Engineering Research Center of Biodiagnosis and Biotherapy,

Second Affiliated Hospital of Xi'an Jiaotong University, Xi'an, China.

Received: 22 December 2016 Accepted: 5 September 2017

Published online: 13 September 2017

\section{References}

1. Chinese Society of Infectious Diseases and Parasitology and Chinese Society of Hepatology, Chinese Medical Association. Guidelines of prevention and treatment for hepatitis C. Zhonghua Gan Zang Bing Za Zhi. 2015;23:906-23.

2. Hajarizadeh B, Grebely J, Dore GJ. Epidemiology and natural history of HCV infection. Nat Rev Gastroenterol Hepatol. 2013:10:553-62.

3. Fusco M, Piselli P, Virdone S, Di Cicco P, Scognamiglio P, De Paoli P, et al. Infection with hepatitis viruses, FIB-4 index and risk of hepatocellular carcinoma in southern Italy: a population-based cohort study. Infect Agent Cancer. 2016;11:54.

4. Durham DP, Skrip LA, Bruce RD, Vilarinho S, Elbasha EH, Galvani AP, et al. The impact of enhanced screening and treatment on hepatitis $C$ in the United States. Clin Infect Dis. 2016;62:298-304

5. Davis $G L$, Alter MJ, El-Serag H, Poynard T, Jennings LW. Aging of hepatitis C virus (HCV)-infected persons in the United States: a multiple cohort model of HCV prevalence and disease progression. Gastroenterology. 2010;138: 513-21. 521. e1-6

6. Janjua NZ, Chong M, Kuo M, Woods R, Wong J, Yoshida EM, et al. Longterm effect of sustained virological response on hepatocellular carcinoma in patients with hepatitis C in Canada. J Hepatol. 2017;66:504-13.

7. lacobellis A, Perri F, Valvano MR, Caruso N, Niro GA, Andriulli A. Long-term outcome after antiviral therapy of patients with hepatitis $C$ virus infection and decompensated cirrhosis. Clin Gastroenterol Hepatol. 2011;9:249-53.

8. Ji FP, Zhang S, Deng H, Li ZF. Efficacy of interferon-based antiviral therapy on the risk of hepatocellular carcinoma of patients with chronic hepatitis C: further evidence in decompensation cirrhosis. J Hepatol. 2013;58:1262-4.

9. van der Meer AJ, Veldt BJ, Feld JJ, Wedemeyer H, Dufour JF, Lammert F, et al. Association between sustained virological response and all-cause mortality among patients with chronic hepatitis $\mathrm{C}$ and advanced hepatic fibrosis. JAMA. 2012;308:2584-93. 
10. Maan R, van der Meer AJ, Hansen BE, Feld JJ, Wedemeyer H, Dufour JF, et al. Effect of thrombocytopenia on treatment tolerability and outcome in patients with chronic HCV infection and advanced hepatic fibrosis. J Hepatol. 2014;61:482-91.

11. Ji FP, Dang SS, Cai ZF, Xue HA, Huang N, Liu LY, et al. Antiviral treatment and long-term clinical outcome of decompensated cirrhotic patients with hepatitis C virus infection. Zhonghua Gan Zang Bing Za Zhi. 2015;23:647-52.

12. lacobellis A, Siciliano M, Perri F, Annicchiarico BE, Leandro G, Caruso N, et al. Peginterferon alfa-2b and ribavirin in patients with hepatitis $C$ virus and decompensated cirrhosis: a controlled study. J Hepatol. 2007;46:206-12.

13. Silva GF, Villela-Nogueira CA, Mello CE, Soares EC, Coelho HS, Ferreira PR, et al. Peginterferon plus ribavirin and sustained virological response rate in HCVrelated advanced fibrosis: a real life study. Braz J Infect Dis. 2014;18:48-52.

14. Sovaldi (sofosbuvir) United States prescribing information. Foster City, CA: Gilead Sciences; 2013. http://www.gilead.com/ /media/Files/pdfs/ medicines/liverdisease/sovaldi/sovaldi_pi.pdf. Accessed 12 Apr 2016.

15. Curry MP, O'Leary JG, Bzowej N, Muir AJ, Korenblat KM, Fenkel JM, et al. Sofosbuvir and velpatasvir for HCV in patients with decompensated cirrhosis. N Engl J Med. 2015;373:2618-28.

16. Modi AA, Nazario H, Trotter JF, Gautam M, Weinstein J, Mantry P, et al. Safety and efficacy of simeprevir plus sofosbuvir with or without ribavirin in patients with decompensated genotype 1 hepatitis $C$ cirrhosis. Liver Transpl. 2016;22:281-6.

17. Bourlière M, Bronowicki JP, de Ledinghen V, Hézode C, Zoulim F, Mathurin $P$, et al. Ledipasvir-sofosbuvir with or without ribavirin to treat patients with HCV genotype 1 infection and cirrhosis non-responsive to previous protease-inhibitor therapy: a randomised, double-blind, phase 2 trial (SIRIUS). Lancet Infect Dis. 2015;15:397-404.

18. Charlton M, Everson GT, Flamm SL, Kumar P, Landis C, Brown RS Jr, et al. Ledipasvir and sofosbuvir plus ribavirin for treatment of HCV infection in patients with advanced liver disease. Gastroenterology. 2015;149:649-59.

19. Cheung MC, Walker AJ, Hudson BE, Verma S, McLauchlan J, Mutimer DJ, et al. Outcomes after successful direct-acting antiviral therapy for patients with chronic hepatitis C and decompensated cirrhosis. J Hepatol. 2016;65:741-7.

20. Foster GR, Irving WL, Cheung MC, Walker AJ, Hudson BE, Verma S, et al. Impact of direct acting antiviral therapy in patients with chronic hepatitis C and decompensated cirrhosis. J Hepatol. 2016;64:1224-31.

21. Gane E, Kowdley KV, Pound D, Stedman CA, Davis M, Etzkorn K, et al. Efficacy of sofosbuvir, velpatasvir, and GS-9857 in patients with HCV genotype 2, 3, 4, or 6 infections in an open-label, phase 2 trial. Gastroenterology. 2016;151:902-9.

22. Nappi A, Perrella A, Bellopede P, Lanza A, Izzi A, Spatarella M, et al. Safety of new DAAs for chronic HCV infection in a real life experience: role of a surveillance network based on clinician and hospital pharmacist. Infect Agent Cancer. 2017;12:12.

23. Chang CY, Nguyen P, Le A, Zhao C, Ahmed A, Daugherty T, et al. Real-world experience with interferon-free, direct acting antiviral therapies in Asian Americans with chronic hepatitis $C$ and advanced liver disease. Medicine (Baltimore). 2017:96:e6128.

24. Lutchman G, Nguyen NH, Chang CY, Ahmed A, Daugherty T, Garcia G, et al. Effectiveness and tolerability of simeprevir and sofosbuvir in nontransplant and post-liver transplant patients with hepatitis C genotype 1. Aliment Pharmacol Ther. 2016:44:738-46.

25. Kozbial K, Moser S, Schwarzer R, Laferl H, Al-Zoairy R, Stauber R, et al. Unexpected high incidence of hepatocellular carcinoma in cirrhotic patients with sustained virologic response following interferon-free direct-acting antiviral treatment. J Hepatol. 2016;65:856-8.

26. Kobayashi M, Suzuki F, Fujiyama S, Kawamura Y, Sezaki H, Hosaka T, et al. Sustained virologic response by direct antiviral agents reduces the incidence of hepatocellular carcinoma in patients with HCV infection. J Med Virol. 2017;89:476-83.

27. Reig M, Mariño Z, Perelló C, Iñarrairaegui M, Ribeiro A, Lens $S$, et al. Unexpected high rate of early tumor recurrence in patients with HCVrelated HCC undergoing interferon-free therapy. J Hepatol. 2016;65:719-26.

28. Conti F, Buonfiglioli F, Scuteri A, Crespi C, Bolondi L, Caraceni P, et al. Early occurrence and recurrence of hepatocellular carcinoma in HCV-related cirrhosis treated with direct-acting antivirals. J Hepatol. 2016;65:727-33.

29. ANRS collaborative study group on hepatocellular carcinoma (ANRS CO22 HEPATHER, CO12 CirVir and CO23 CUPILT cohorts). Lack of evidence of an effect of direct-acting antivirals on the recurrence of hepatocellular carcinoma: Data from three ANRS cohorts. J Hepatol. 2016;65:734-40.
30. Ji D, Chen GF, Wang C, Wang YD, Shao Q, Li B, et al. Twelve-week ribavirin-free direct-acting antivirals for treatment-experienced Chinese with HCV genotype 1b infection including cirrhotic patients. Hepatol Int. 2016;10:789-98.

31. Zeng QL, Xu GH, Zhang JY, Li W, Zhang DW, Li ZQ, et al. Generic ledipasvirsofosbuvir for patients with chronic hepatitis C: A real-life observational study. J Hepatol. 2017:66:1123-9.

32. Ji FP, Zhang S, Huang N, Deng H, Li ZF. Splenectomy prior to antiviral therapy in patients with HCV related decompensated cirrhosis. Braz J Infect Dis. 2013;17:601-5.

33. Ji FP, Zhou R, Wang WJ, Bai D, He CN, Cai ZF, et al. High post-treatment afetoprotein levels and aspartate aminotransferase-to-platelet ratio index predict hepatocellular carcinoma in hepatitis C virus decompensated cirrhotic patients with sustained virological response after antiviral therapy. J Interf Cytokine Res. 2017;37:362-8.

34. Planas R, Balleste B, Alvarez MA, Rivera M, Montoliu S, Galeras JA, et al Natural history of decompensated hepatitis $C$ virus-related cirrhosis. A study of 200 patients. J Hepatol. 2004;40:823-30.

35. Lawson A, Hagan S, Rye K, Taguri N, Ratib S, Zaitoun AM, et al. The natural history of hepatitis C with severe hepatic fibrosis. J Hepatol. 2007:47:37-45.

36. European Association for Study of Liver. EASL recommendations on treatment of hepatitis C 2015. J Hepatol. 2015;63:199-236.

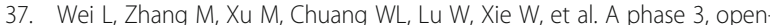
label study of daclatasvir plus asunaprevir in Asian patients with chronic hepatitis $C$ virus genotype $1 \mathrm{~b}$ infection who are ineligible for or intolerant to interferon alfa therapies with or without ribavirin. J Gastroenterol Hepatol. 2016:31:1860-7.

38. Saxena V, Nyberg L, Pauly M, Dasgupta A, Nyberg A, Piasecki B, et al. Safety and efficacy of simeprevir/sofosbuvir in hepatitis C-infected patients with compensated and decompensated cirrhosis. Hepatology. 2015;62:715-25.

39. Desnoyer A, Pospai D, Lê MP, Gervais A, Heurgué-Berlot A, Laradi A, et al. Pharmacokinetics, safety and efficacy of a full dose sofosbuvir-based regimen given daily in hemodialysis patients with chronic hepatitis C. J Hepatol. 2016:65:40-7.

40. Nazario HE, Ndungu M, Modi AA. Sofosbuvir and simeprevir in hepatitis C genotype 1 patients with end-stage renal disease on hemodialysis or GFR <30mL/min. Liver Int. 2016;36:798-801.

41. AASLD/IDSA HCV Guidance Panel. Hepatitis C guidance: AASLD-IDSA recommendations for testing, managing, and treating adults infected with hepatitis C virus. Hepatology. 2015;62:932-54.

42. Omata M, Kanda T, Wei L, Yu ML, Chuang WL, Ibrahim A, et al. APASL consensus statements and recommendation on treatment of hepatitis $C$. Hepatol Int. 2016;10:702-26.

\section{Submit your next manuscript to BioMed Central and we will help you at every step:}

- We accept pre-submission inquiries

- Our selector tool helps you to find the most relevant journal

- We provide round the clock customer support

- Convenient online submission

- Thorough peer review

- Inclusion in PubMed and all major indexing services

- Maximum visibility for your research

Submit your manuscript at www.biomedcentral.com/submit
) Biomed Central 